\title{
PROBABILISTIC SEISMIC HAZARD ANALYSIS OF PEAK GROUND ACCELERATION FOR MAJOR REGIONAL NEW ZEALAND LOCATIONS
}

\author{
Brendon A. Bradley ${ }^{1}$, Misko Cubrinovski ${ }^{2}$ and Frederick Wentz ${ }^{3}$
}

(Submitted November 2020; Reviewed March 2021; Accepted May 2021)

\begin{abstract}
This paper presents site-specific probabilistic seismic hazard analysis (PSHA) results at 24 locations throughout New Zealand (NZ). Specifically, peak ground acceleration (PGA) hazard curves for two generic soft soil conditions are considered. For specific return periods of interest, seismic hazard disaggregation is used to obtain the percentage contributions of various seismic sources to the hazard, including metrics such as mean earthquake magnitude used for simplified geotechnical calculations. The seismic hazard analyses utilise concensus models for seismic source and ground-motion characterisation, including consideration of alternative ground-motion models. The analyses therefore represent an appreciable improvement relative to the science that underpin current loading standards [e.g., 1,2]. Consequently, we advocate the use of these results as a scientific basis for potential revisions to standards and guidance documents that characterise seismic hazard via PGA.
\end{abstract}

\section{INTRODUCTION}

The PSHA method has formed the internationally-accepted scientific approach for the consideration of seismic hazards for the past 60 years [3]. Seismic design standards in New Zealand (NZ) [e.g., 1,2] are based PSHA outputs [4], with adjustments in numerical values based on adopted approaches to facilitate practical implementation.

Of the myriad of different ground-motion intensity measures to quantify seismic hazard in a simple manner, PGA remains a commonly utilised parameter, particularly in geotechnical earthquake engineering problems, for example, simplified liquefaction triggering assessments [5]. For the majority of structures and infrastructure in NZ, PGA values for seismic design (and assessment) are specified via standards and guidance documents, with a small proportion of cases making direct use of a sitespecific PSHA [6]. The two most common approaches adopted in NZ practice over the past decade are to obtain PGA values from: (i) the NZS1170.5 [1] design response spectra (SA) for a vibration period of $T=0$ (i.e., $S A(T=0)=P G A$ ), or (ii) directly from the NZ Transport Agency Bridge Manual (NZTABM) [2], as described in the NZ Geotechnical Society (NZGS) guidelines [7].

Comparisons of the numerical values obtained from these two guidance $^{1}$ documents for magnitude-weighted PGA illustrates significant variations across NZ [8], despite the fact that they should be based on the same underlying PSHA approach. Additionally, the scientific models for earthquake sources and ground-motion shaking in these documents are also nearly 20 years old [4], and therefore do not reflect current understanding

\footnotetext{
${ }^{1}$ For brevity we refer to these as 'guidance' documents, albeit acknowledging that there is a difference between (binding) standards and (non-binding) guidance documents.
}

in the scientific field of seismic hazard analysis.

Given the aforementioned issues, this paper documents research that was undertaken to obtain the PGA seismic hazard using site-specific PSHA for multiple locations throughout NZ. The analyses were undertaken in the context of obtaining results for direct use in geotechnical earthquake engineering calculations; specifically simplified liquefaction triggering assessments. That said, these results are also applicable (keeping in mind the subsequently stated assumptions and limitations) in a general sense to understand the spatial variation in seismic hazard across NZ as well as the deviation between present-day understanding and that of current guidance documents, whose scientific basis is nearly two decades old.

The subsequent section discusses the seismic hazard analysis details, specifically the PSHA and disaggregation calculations and underpinning seismic source and ground-motion models adopted. The 24 selected locations are then discussed, and hazard analysis results presented at several example locations. This is proceeded by a high-level discussion of the aggregated results for all 24 locations. Finally, the implications of this study are summarised.

A companion paper [8] provides further interpretation of the results from this hazard study for use in geotechnical assessment and design.

\section{SEISMIC HAZARD ANALYSIS DETAILS}

\section{PSHA Equations}

The seismic hazard curves for PGA were obtained from conventional PSHA, which can be summarised via the equation:

\footnotetext{
${ }^{1}$ Professor, Department of Civil and Natural Resources Engineering, University of Canterbury, Christchurch, brendon.bradley@canterbury.ac.nz (Member)

${ }^{2}$ Professor, Department of Civil and Natural Resources Engineering, University of Canterbury, Christchurch (Fellow)

${ }^{3}$ Director, Wentz-Pacific Limited, Napier (Member)
} 


$$
\lambda(P G A>x)=\sum_{i=1}^{N_{R u p}} P\left(P G A>x \mid r u p_{i}\right) \lambda\left(\operatorname{rup}_{i}\right)
$$

where $\lambda(P G A>x)$ is the mean annual rate of a ground motion with PGA exceeding the value $x ; \lambda\left(\right.$ rup $\left._{i}\right)$ is the rate of occurrence of earthquake rupture rup r $_{i}$, provided by the Seismic Source Model (SSM); $P\left(P G A>x \mid r u p_{i}\right)$ is the probability that $P G A>x$ given $r u p_{i}$, provided by a Ground-Motion Model (GMM); and the summation represents the aggregation over all $N_{R u p}$ ruptures in the SSM that pose a hazard to the site of interest.

Both the SSM and GMM contain uncertainty, and it is common to consider multiple models to address this modelling (epistemic) uncertainty explicitly. It is also common to consider the hazard curve outputs in the form of Return Period $(R P)$, which is related to annual rate of exceedance via $R P(P G A>x)=$ $1 / \lambda(P G A>x)$.

Because seismic hazard curves represent the aggregate contribution of all potential earthquake ruptures at a given location, then it is also of interest to disaggregate the total seismic hazard to determine the relative contribution of individual ruptures. The probability of each rupture can be determined from:

$$
P\left(\operatorname{rup}_{i} \mid P G A>x\right)=\frac{P\left(P G A>x \mid r u p_{i}\right) \lambda\left(\text { rup }_{i}\right)}{\lambda(P G A>x)}
$$

Further details on seismic hazard analysis principles can be found in Kramer [9] and Baker et al. [10], while Bradley [6] provides discussion on the benefits of its use in a NZ context.

\section{Seismic Source Model (SSM)}

The SSM describes the location, characteristics, and rate of occurrence of all earthquake ruptures in the region of interest. Characteristics include details such as, e.g., tectonic type, magnitude, and focal mechanism, among others. For application in a regional context of NZ, the model of Stirling et al. [11] provides the most recent nationwide consensus model, and was adopted in this study ${ }^{2}$. It is acknowledged that there continues to be advancements in SSM components (e.g., active faulting [13], time-dependent treatment of distributed seismicity [14], and insights from retrospective and prospective testing [15]), and a revision to develop a supersceeding model has recently commenced. Rather than attempt to make incremental changes to this 2010 concensus model given the science advancements in the intervening time period, which would naturally be subject to proponents and opponents, it was preferred to retain the use of a consensus model that already represents an appreciable science advancement over those models used in the development of Standards New Zealand [1], and consequently NZ Transport Agency [2].

\section{Ground-Motion Models (GMMs)}

GMMs provide the probability distribution of ground-motion intensity (PGA in the context of this study) at a location of interest resulting from a specific rupture. The variation in available GMMs is known to have an appreciable effect on PSHA results, and therefore it is conventional to consider multiple such models in order to (partially) reflect epistemic (modelling) uncertainty [10]. In this specific study, six different GMMs were considered across the three tectonic environments of relevance. For Active Shallow Crustal tectonic sources, the adopted models were Bradley [16], Abrahamson et al. [17], Campbell and

${ }^{2}$ Inclusion of aftershock activity in the Canterbury region was additionally included based on the model described in Bradley [12].
Bozorgnia [18], and Boore et al. [19]. The Bradley et al. model, developed specifically for $\mathrm{NZ}$ conditions, was assigned a weight of 50\%, with the remaining three models each assigned $16.6 \%$. For tectonic sources in Volcanic environments the Bradley et al. model was adopted with a weight of $100 \%$, due to other models not explicitly accounting for the additional anelastic attenuation in the Taupo Volcanic Zone ${ }^{3}$. For Subduction Interface and Subduction Slab conditions, the models of Zhao et al. [20] and Abrahamson et al. [21] were adopted, with respective weights of $25 \%$ and $75 \%$. The basis for these model weights draws upon the performance of these models against $\mathrm{NZ}$ validation data, as well as the recognised extrapolation required beyond the validation data to the seismic scenarios that dominate hazard, as discussed in Bradley [22],Van Houtte [23], among others.

\section{Guidelines and Standards for Comparison}

Given the scope of this study, comparison is primarily made with two principal documents - NZTA-BM [2] and NZS1170.5 [1]. The NZTA-BM provides guidance for both structural design of bridges, and also geotechnical-specific guidance for liquefaction and the stability and displacement of soil structures. NZS1170.5 is a structural loading standard, but has also historically been used for determining PGA values for geotechnical applications (see Cubrinovski et al. [8] for further discussion).

While these two guidance documents are routinely used in practice, it is important to note that, in the authors' view, they both contain scientific aspects that make them sub-optimal for the determination of PGA values (and associated earthquake moment magnitudes) for geotechnical applications. Firstly, NZS1170.5 explicitly notes its focus on structural applications, implicitly alluding to the fact that the parametric functions presented for determining response spectral design loadings are not intended to be used for computing PGA values. NZS1170.5 is also based on the 'larger component' definition of horizontal groundmotion intensity [e.g., 24], as opposed to the 'geometric mean' (or rotation-independent $50^{\text {th }}$ percentile) definition that is the basis for liquefaction triggering models [e.g., 5,25]. Finally, NZS1170.5 adopts a 'magnitude weighting' definition in order to reduce the 'peaked' spectra at short vibration periods that resulted from the adopted GMMs in the hazard calculation at the time [22,26] (see discussion in Cubrinovski et al. [8]). McVerry [4] provides further details on the manner in which NZS1170.5 is obtained from underpinning PSHA calculations.

In a similar vein, NZTA-BM contains 'updated' PSHA results from those in NZS1170.5 that are intended for use in geotechnical applications. Un-weighted PGA values are provided, in order to allow geotechnical analysts to apply magnitude scaling directly. Magnitude values are also provided as a so-called $e f$ fective magnitude. Unfortunately, the methodology behind the calculation of the seismic hazard PGA values and effective magnitudes are not elaborated upon in NZTA-BM, and as we will show through comparison with site-specific hazard analysis values in this paper, these effective magnitude values deviate significantly from the disaggregation mean magnitude values that should ultimately be used for geotechnical calculations (See Appendix).

Despite the limitations outlined in the above two paragraphs, subsequent figures illustrate comparisons between the obtained site-specific PSHA results computed for this study and those of NZTA-BM and NZS1170.5. In comparing such figures, it is emphasised that the site-specific PSHA and NZTA-BM re-

${ }^{3}$ These sources make small contributions for the locations considered, so this modelling decision is of little practical impact. 
Table 1: Geographic locations and corresponding parameter values used in seismic hazard descriptions in NZS1170.5 and NZTA-BM.

\begin{tabular}{lcc}
\hline Location & NZS1170.5 $Z$ & NZTA-BM $C_{0,1000}$ \\
\hline Arthurs Pass & 0.6 & 0.62 \\
Auckland & 0.13 & 0.19 \\
Blenheim & 0.33 & 0.42 \\
Christchurch & 0.3 & - \\
Dunedin & 0.13 & 0.25 \\
Gisborne & 0.36 & 0.41 \\
Greymouth & 0.37 & 0.5 \\
Hamilton & 0.16 & 0.28 \\
Invercargill & 0.17 & 0.26 \\
Napier & 0.38 & 0.43 \\
Nelson & 0.27 & 0.43 \\
New Plymouth & 0.18 & 0.33 \\
Oamaru & 0.13 & 0.24 \\
Palmerston North & 0.38 & 0.44 \\
Queenstown & 0.32 & 0.42 \\
Rotorua & 0.24 & 0.39 \\
Taupo & 0.28 & 0.42 \\
Tauranga & 0.2 & 0.34 \\
Timaru & 0.15 & 0.23 \\
Wanaka & 0.3 & 0.42 \\
Wellington & 0.4 & 0.45 \\
Whakatane & 0.3 & 0.46 \\
Whanganui & 0.25 & 0.37 \\
Whangarei & 0.1 & 0.16 \\
\hline
\end{tabular}

sults are for un-weighted PGA values, whereas NZS1170.5 results are for weighted PGA values. As a result, in subsequent figures, the results of NZS1170.5 are referred to as ' $P G A_{7.5}$ '. Cubrinovski et al. [8] more rigorously compare the resulting magnitude-weighted PGA amplitudes in the context of their application.

\section{GEOGRAPHIC LOCATIONS OF INTEREST}

Figure 1 illustrates the 24 locations at which PGA hazard curves were computed using site-specific PSHA, and Table 1 provides the specific parameter values used in NZS1170.5 and NZTA$\mathrm{BM}$ for computing the equivalent PGA hazard values based on these documents.

\section{Site Conditions}

In order to conduct the PSHA at each of the locations in Table 1, definitions of the surficial soil conditions are required. The majority of the GMMs utilise the $30 \mathrm{~m}$ average shear-wave velocity, $V_{S, 30}$, to describe the shallow site conditions. The Zhao et al. model uses a discrete site classification scheme, which was mapped to corresponding $V_{S, 30}$ values as described by Bradley [16].

The spatial variation of $V_{S, 30}$ values in each region based on available models [27] largely resides between $V_{S, 30}=200-300$ $\mathrm{m} / \mathrm{s}$. In addition, considering the primary application (geotechnical assessment) of this study, two different reference site conditions of $V_{S, 30}=200$ and $300 \mathrm{~m} / \mathrm{s}$ were selected for the PSHA calculations. The subsequently presented figures illustrate that there are relatively minor differences between the PSHA results for these two different $V_{S, 30}$ values, relative to the differences of the PHSA results to those of the existing guidance documents. Therefore, primary focus is given to the $V_{S, 30}=300 \mathrm{~m} / \mathrm{s}$ results, with further justification provided in Cubrinovski et al. [8].

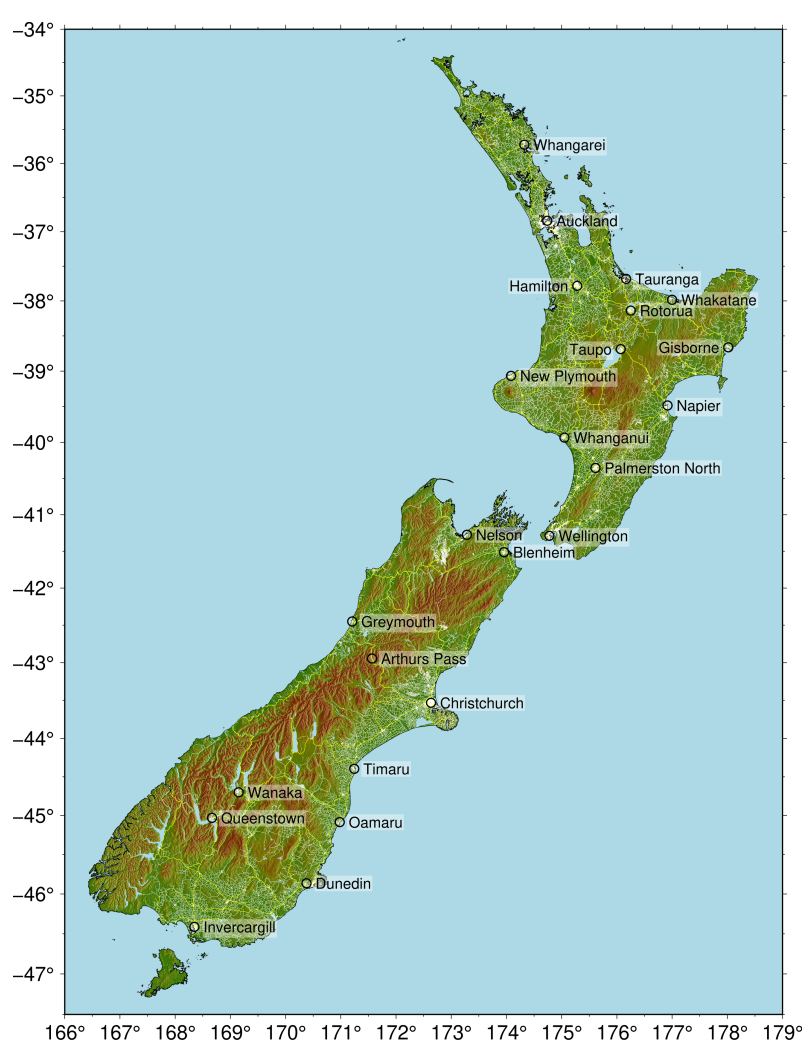

Figure 1: Geographic locations of 24 site at which site-specific PGA hazard calculations were performed.

\section{Spatial Discretisation of Locations}

Another aspect considered was the degree to which the seismic hazard varies over spatial distances on the order of a few $\mathrm{km}$ - of relevance for the footprint of NZ's largest cities. Spatial variations in site-specific seismic hazard are affected by: (i) the variation in soil conditions that occur; and (ii) the variation in source-to-site distances to earthquake ruptures (i.e., faults). The prior subsection already addressed the consideration of two different generic descriptors of soil conditions, and therefore the remaining effect is that associated with varying source-to-site distances. Sensitivity analyses illustrate that over spatial distances of 1-2 km, without changing soil conditions, the seismic hazard varies by a maximum of a few percent for the highseismicity locations considered, and significantly less for lowseismicity locations that are not proximal to modelled active faults. Therefore, in the context of the focus of this study, a single geographic coordinate was adopted for each of the 24 locations of interest. This approach is also consistent with the definition of PGA values in the guidance documents used here for comparison, but this illustrates one of several differences between the generic PSHA results presented here and those of truly site-specific PSHA studies, as discussed subsequently.

\section{HAZARD RESULTS}

This section firstly presents example PSHA results at several locations to provide insight and introduce several terms to quantify the results. It is followed by an aggregate analysis of the results for all 24 sites.

In discussing results in this section, use of the phrases underestimation and over-estimation are made for the guidance document-based PGA hazard values with respect to the sitespecific PSHA results. This terminology is adopted on the basis that the site-specific PSHA results are considered the best-estimate of the true seismic hazard at the present time. 


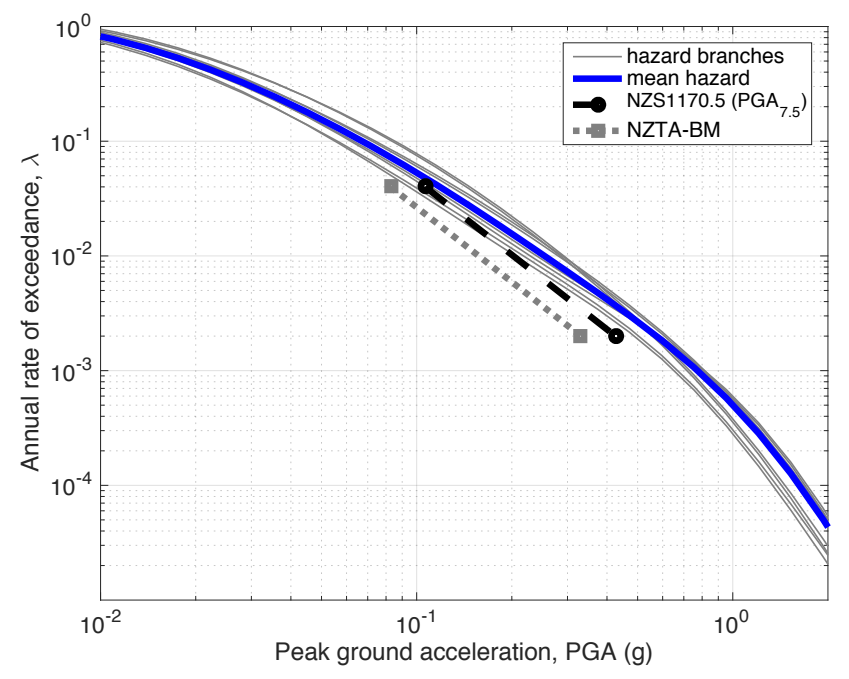

(a) PGA hazard curve.

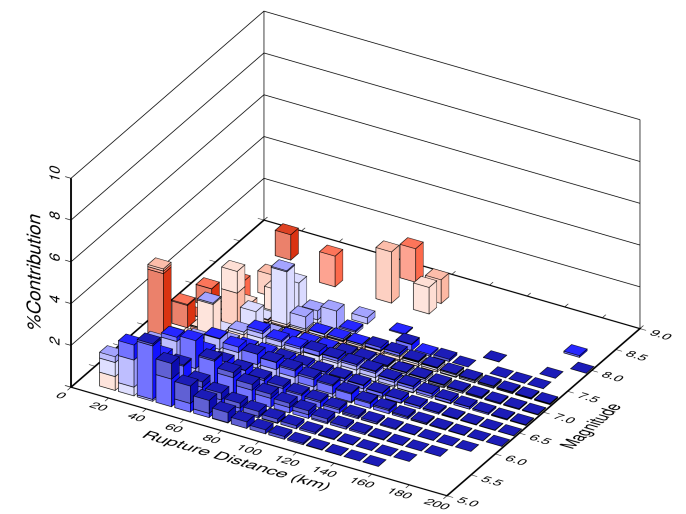

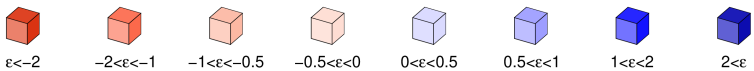

(b) Disaggregation for $R P=25 y r(\bar{M}=6.35)$.

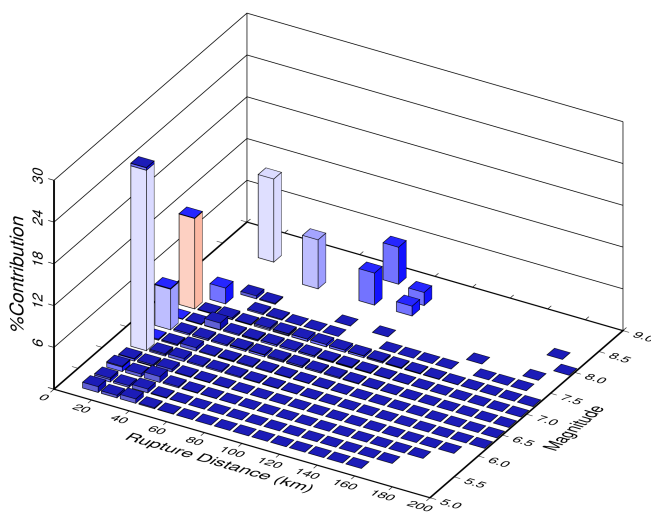

$\bigoplus_{\varepsilon<-2} \bigoplus_{-2<\varepsilon<-1} \bigotimes_{-1<\varepsilon<-0.5} \bigoplus_{-0.5<\varepsilon<0} \bigoplus_{0<\varepsilon<0.5} \bigotimes_{0.5<\varepsilon<1} \bigoplus_{1<\varepsilon<2} \bigoplus_{2<\varepsilon}$

(c) Disaggregation for $R P=500 y r(\bar{M}=7.14)$.

Figure 2: Napier PGA seismic hazard curve and disaggregation for two return periods $(R P)$.

\section{Example Results at Specific Locations}

Figures 2-4 present the seismic hazard curves and disaggregation results for Napier, Nelson, and Wellington. For each of the figures, panel (a) illustrates the PGA seismic hazard curve for $V_{S, 30}=300 \mathrm{~m} / \mathrm{s}$, while panels (b) and (c) illustrate the disaggregation results for the 25 and 500 year RP. In the (a) panel results,

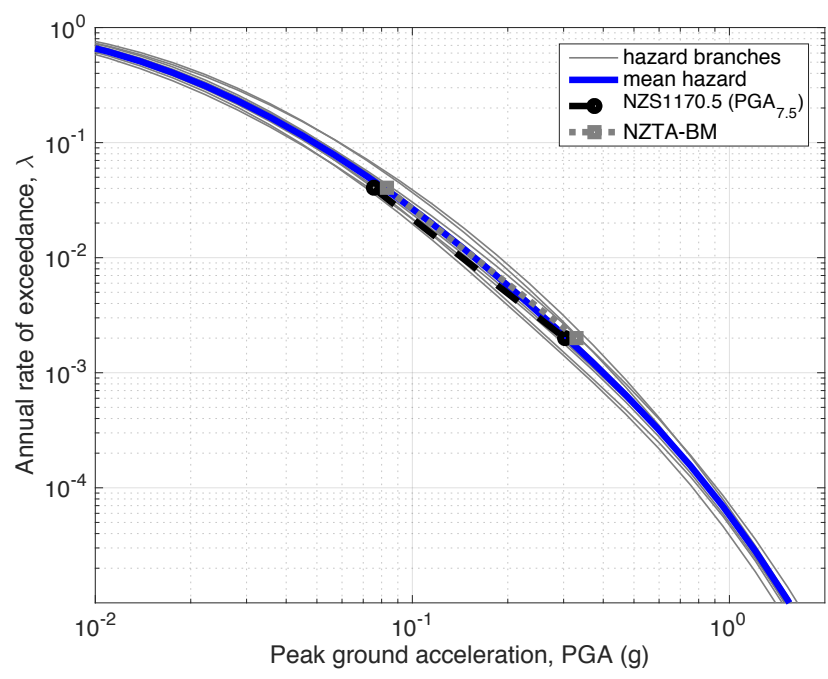

(a) PGA hazard curve.
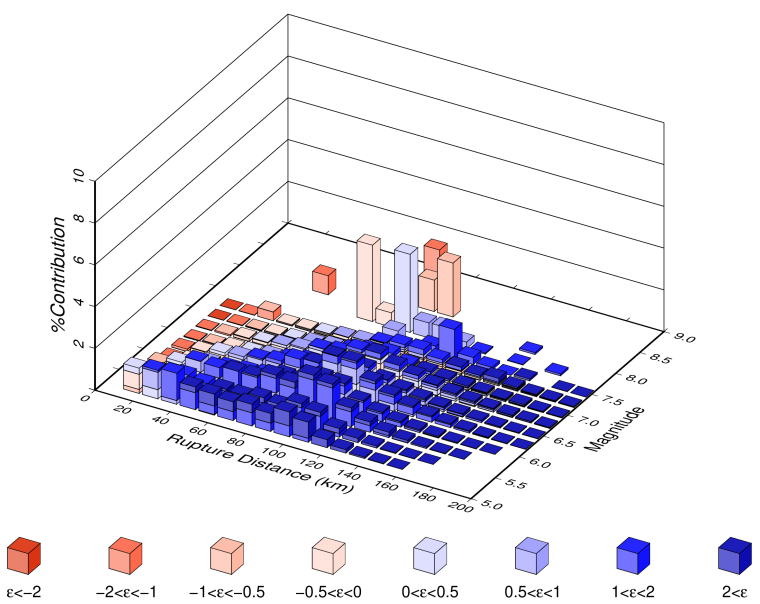

(b) Disaggregation for $R P=25 y r(\bar{M}=6.31)$.
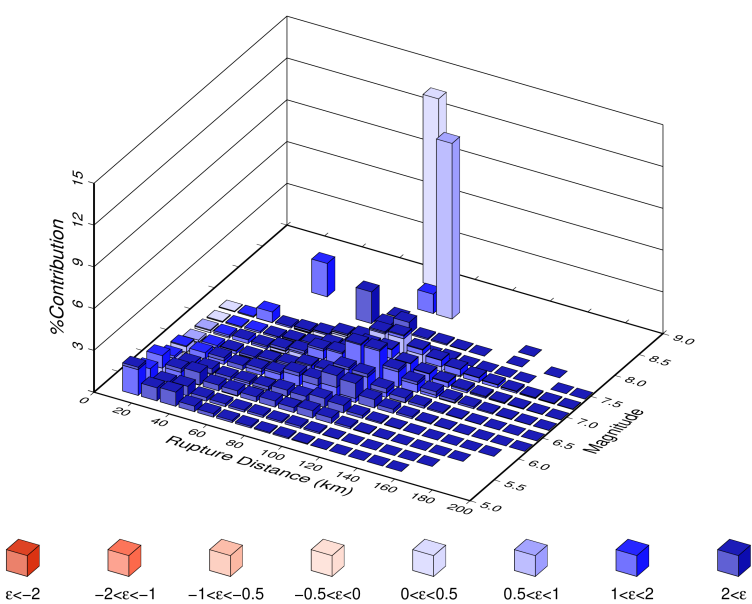

(c) Disaggregation for $R P=500 y r(\bar{M}=7.01)$.

Figure 3: Nelson PGA seismic hazard curve and disaggregation for two return periods $(\mathrm{RP})$.

the seismic hazard for each 'branch' of the logic tree, reflecting the multiple GMMs considered, is shown as well as the mean hazard. For comparison the NZS1170.5 and NZTA-BM guideline values for the 25 and 500 year RPs and Site Class D are also depicted. It is re-emphasised that the PGA hazard curves in panel (a) for each figure are 'un-weighted' PGA values for the site-specific PSHA and NZTA-BM, but magnitude-weighted for 


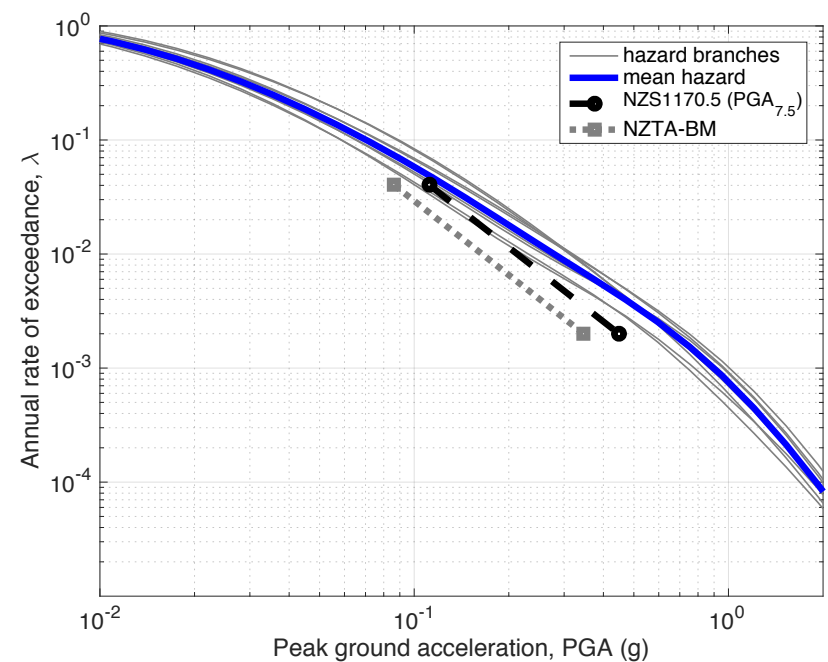

(a) PGA hazard curve.

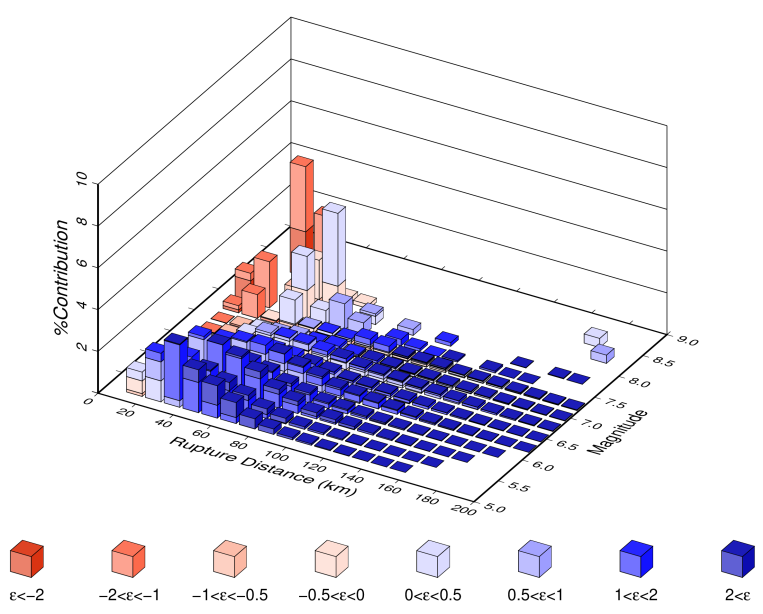

(b) Disaggregation for $R P=25 y r(\bar{M}=6.47)$.

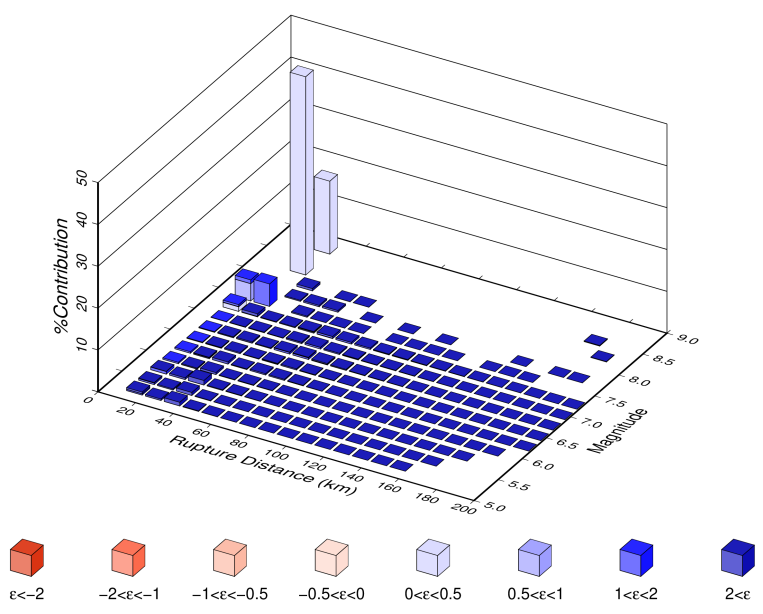

(c) Disaggregation for $R P=500 y r(\bar{M}=7.71)$. Figure 4: Wellington PGA seismic hazard curve and
disaggregation for two return periods $(R P)$.

\section{NZS1170.5 (as previously discussed).}

Comparison across the three sites illustrates that, in both Napier and Wellington, the mean hazard from the site-specific PSHA results are higher than both guidance document-based hazard values, and that the NZTA-BM results are lower than those of NZS1170.5. The under-estimation of the site-specific haz- ard from the guidance documents is more pronounced at the 500 year RP, particularly in Wellington, where numerous largemagnitude sources with frequent rates of occurrence exist. In contrast, for Nelson, the site-specific and guidance documents are very similar. Other locations, that are subsequently discussed in the aggregated results, do exhibit site-specific PSHA results that are lower than those prescribed in these guidance documents. There is a relatively strong correlation between over-/under-prediction and the level of seismicity, with high-seismic hazard locations (e.g., Wellington, Napier) being under-estimated, and low-seismic hazard locations being overestimated in current guidance documents ${ }^{4}$.

The uncertainty due to alternative GMMs, reflected in the individual hazard branches, also has an appreciable effect on the seismic hazard. For example, the 500 year RP hazard in Wellington has hazard branch values that range from approximately $0.55 \mathrm{~g}$ to $0.75 \mathrm{~g}$, with a mean of $0.68 \mathrm{~g}$.

The seismic hazard disaggregation results ${ }^{5}$ in panels (b) and (c) of Figures 2-4 provide the percentage contribution of different seismic sources binned into discrete magnitude and distance ranges, with the mean magnitude, $\bar{M}$, noted in the figure caption. There is a general trend that the disaggregation for the 25 year RP is comprised of a greater number of contributing sources than the 500 year RP, particularly distributed seismicity sources ${ }^{6}$. The prevalence of a small number of faults for the 500 year RP is common in all three locations shown (but not that case for all 24 considered sites). For Napier, these correspond to moderate-magnitude near-source Active Shallow Crustal sources (distances, $R_{\text {rup }}<20 \mathrm{~km}$ ), as well as the proximal Subduction Interface sources $(M>8)$. For Nelson, the Alpine Fault and Wairarapa Faults $(M>8)$ are most prevalent, but there remains a significant contribution of distributed seismicity with $M=[5,7.2]$ and $R_{\text {rup }}<140 \mathrm{~km}$. In Wellington, the nearby Wellington and Wairarapa Active Shallow Crustal, and Hikurangi Subduction Interface sources, completely dominate the hazard and result in $\bar{M}=7.71$.

\section{Effect of $V_{S, 30}$}

Figure 5 illustrates the mean site-specific hazard curves for the three previously discussed locations and two different $V_{S .30}$ conditions of 200 and $300 \mathrm{~m} / \mathrm{s}$. In all three instances, the difference between the two hazard curves are relatively small, particularly for $\mathrm{RP}<500 \mathrm{yrs}$. From a physics perspective, at the two higher seismic hazard sites of Napier and Wellington, the curves for 200 and $300 \mathrm{~m} / \mathrm{s}$ can be seen to 'cross over', reflecting the fact that nonlinear soil response at large ground-motion intensities leads to near-surface deamplification of ground motion, and a subsequently smaller PGA hazard for $V_{S, 30}=200 \mathrm{~m} / \mathrm{s}$ than for $V_{S, 30}=300 \mathrm{~m} / \mathrm{s}$. The effect of this nonlinear soil behaviour is less notable in Nelson, because of the smaller PGA values for a given exceedance rate of interest. As a result of these small differences, and attempting to balance practical simplicity, attention is focused on the results for $V_{S, 30}=300 \mathrm{~m} / \mathrm{s}$ in examining the results for all 24 sites in the next section (with further discussion of the relative effect of $V_{S, 30}$ in Cubrinovski et al. [8]).

${ }^{4}$ In many such locations the design levels are purposefully greater than those from site-specific PSHA, and equal to some minimum threshold, in order to achieve a minimum level of resilience.

${ }^{5}$ The coloring reflects the 'epsilon' value of the ground-motion intensity from each seismic source, indicating the exceedance probability from the ground-motion distribution (see Baker et al. [10, Chapter 7]).

${ }^{6}$ Which reflect potential earthquakes on faults that are not explicitly modelled as individual sources. 


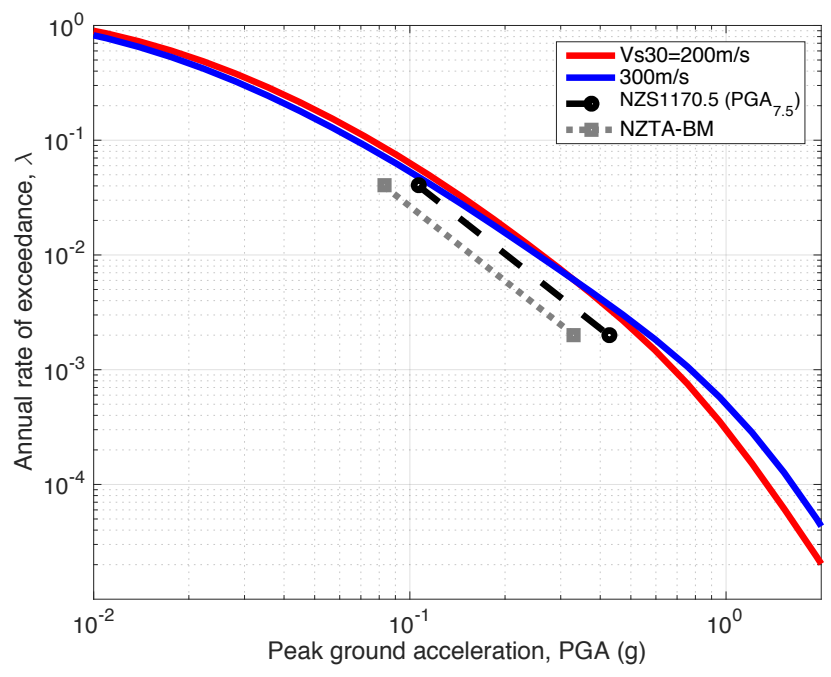

(a) Napier.

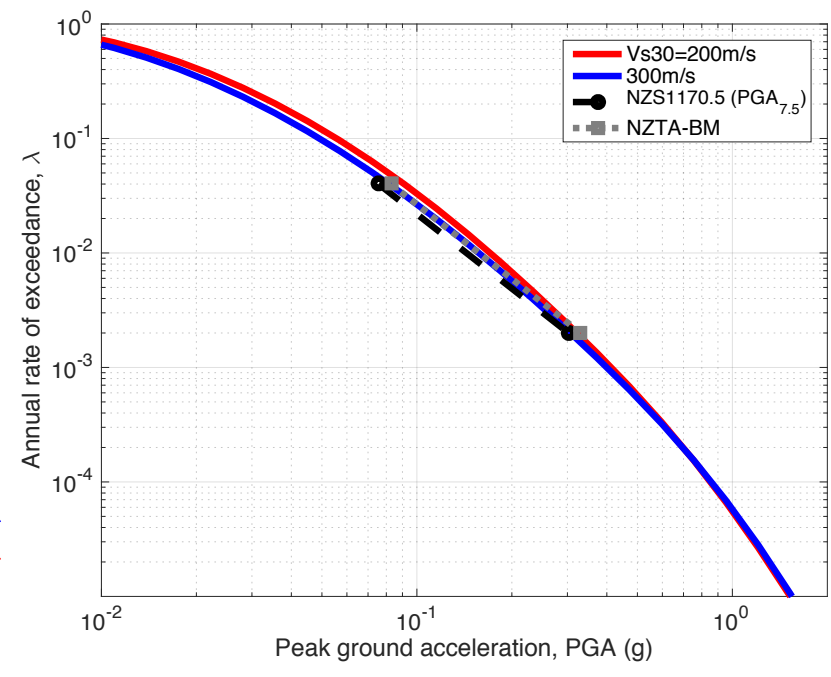

(b) Nelson.

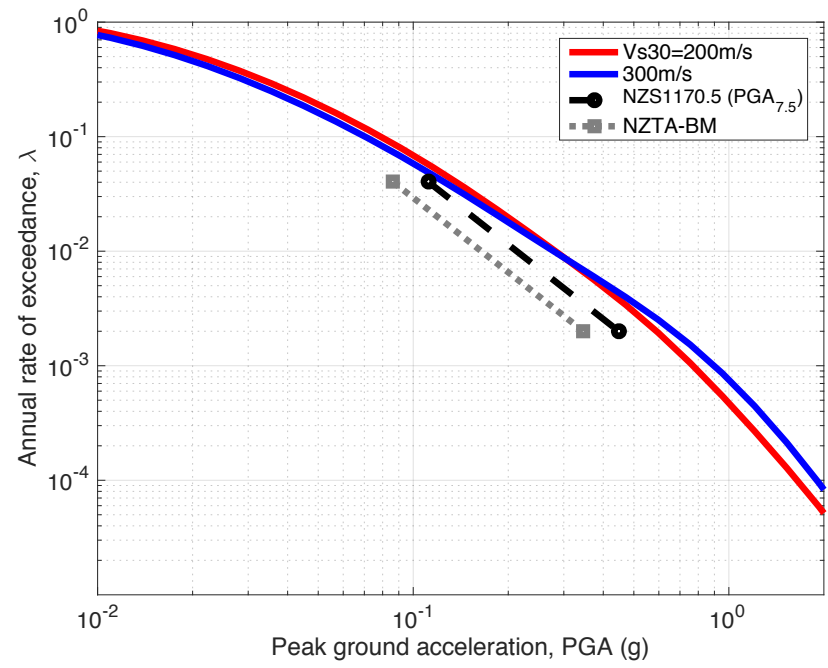

(c) Wellington.

Figure 5: Comparison of mean site-specific PGA hazard curves for $V_{S, 30}=200$ and $300 \mathrm{~m} / \mathbf{s}$.

\section{Aggregate Results}

The format of results discussed in the previous subsection were obtained for each of the 24 locations given in Figure 1. The paragraphs below discuss several summative metrics that describe the salient features of the seismic hazard curves and disaggregation in order to concisely discuss all sites.

\section{PGA Hazard at RPs of 25 and 500 Years}

Figure 6 presents the 25 and 500 year return period PGA values from the site-specific PSHA compared to those from NZS1170.5 and NZTA-BM. Additionally, Figure 7 provides a direct one-to-one comparison of the 25 and 500 year return period PGA values from site-specific and NZTA-BM; NZS1170.5 PGA values are not explicitly shown because they implicitly already have magnitude weighting (see Cubrinovski et al. [8]). In Figure 7, points below the 1:1 line indicate site-specific values that are greater than the NZTA-BM values, and vice versa for those above the line. With Arthur's Pass as the one exception, Figure 7 illustrates the trend of NZTA-BM-based values underestimating the site-specific seismic hazard in high seismicity regions, and over-estimating it in low seismicity regions. This under-estimation is particularly significant, and further exacerbated by, the effective magnitudes prescribed being appreciably lower than the mean magnitudes obtained from site-specific
PSHA, discussed briefly below and in Cubrinovski et al. [8].

Because of the multitude of factors that influence seismic hazard, combined with differences that result from the codification of direct PSHA results, it is difficult to isolate all the reasons for the lower values from NZS1170.5 and NZTA-BM compared to the PSHA results from this study in high seismicity regions. One notable factor is that many of these instances occur along the east coast of the North Island, proximal to the Hikurangi subduction interface. A comparison of the 2012-era source model used in this study [11], with the 2002-era model on which NZS1170.5 and NZTA-BM are based [28], illustrates that the total seismic moment rate $\left(\dot{M}_{O}\right)$ for all modelled events on the Hikurangi subduction interface are $\dot{M}_{O}^{2012}=2.0 \times 10^{19} \mathrm{Nm}$, and $\dot{M}_{O}^{2002}=1.3 \times 10^{19} \mathrm{Nm}$, respectively. This $50 \%$ larger seismic moment rate in the 2012-era model has a first-order effect on the higher seismic hazard predicted for sites where this subduction interface makes an appreciable contribution to the seismic hazard - which are east coast North Island, and upper South Island locations.

\section{Mean Magnitude ( $\bar{M})$}

Figure 8 provides a comparison of the mean magnitude values from the site-specific hazard analysis and $M_{e f f}$ from NZTA-BM across the 24 sites considered, for both the 25 and 500 year RPs. 


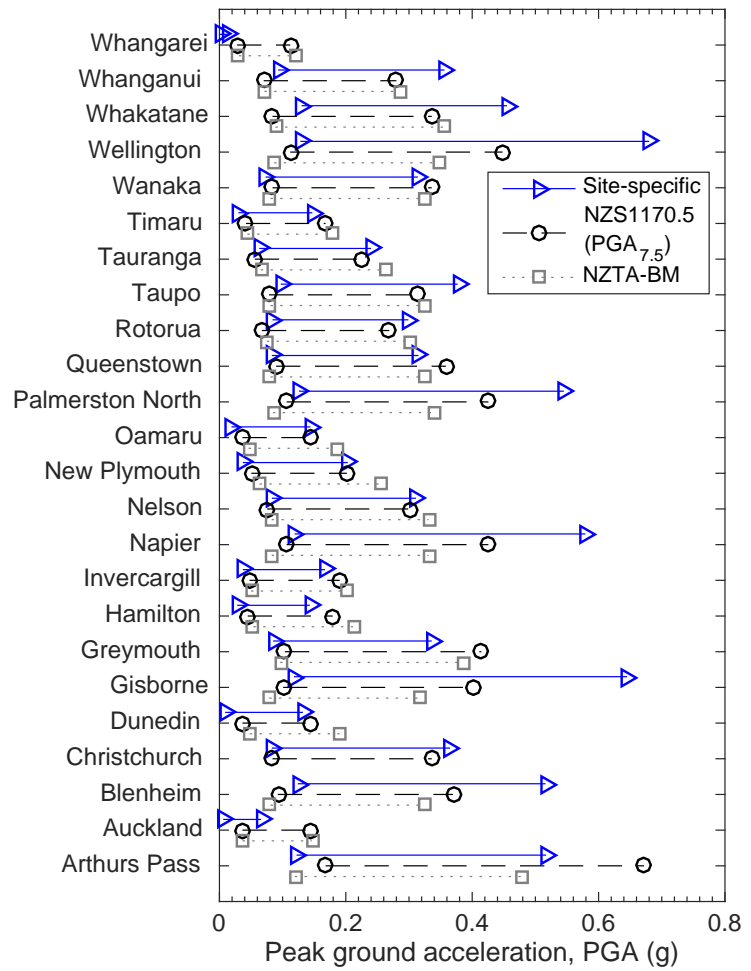

Figure 6: Comparison of the 25 and 500 year return period PGA values obtained from site-specific PSHA and the two guidance documents. Note the NZS1170.5 values are $P G A_{7.5}$.

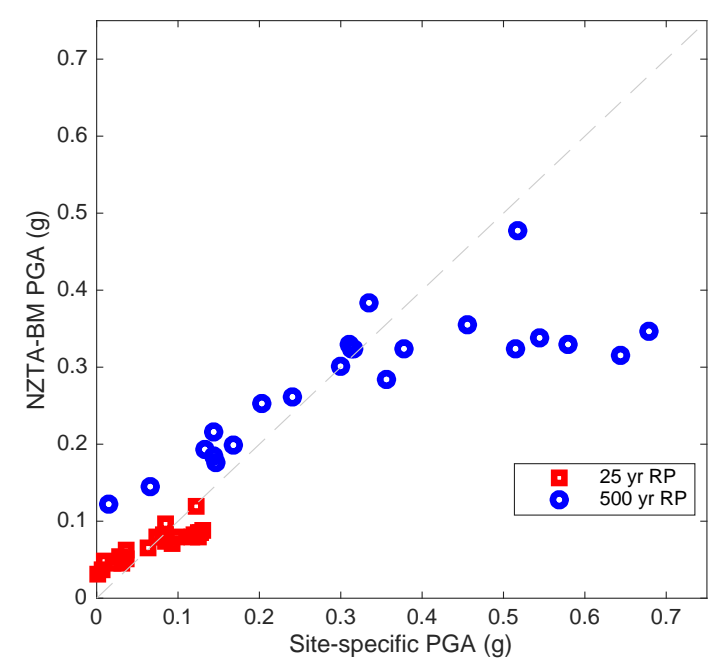

Figure 7: One-to-one comparison of site-specific and guidance document PGA values for the 500 year Return Period.

As alluded to in the context of the three sites examined in detail in the prior sub-section, there is a general trend of increasing mean magnitude for higher seismic hazard locations, and also with increasing RP.

Figure 8 also illustrates the effective magnitudes from NZTABM. NZTA-BM provides two values of effective magnitude (for 50-250 and 500-2500 year RP ranges), although for some sites these two effective magnitude values are numerically identical.
The principal observation in Figure 8 is the effective magnitudes for high-seismicity sites are substantially lower than the mean magnitudes from the site-specific hazard analysis. For example, Wellington has effective magnitudes of $[6.2,7.1]$ from NZTA-BM, but mean magnitudes of [6.47,7.71] from the sitespecific hazard analysis (for the 25 and 500 year RPs). The individual contributions of earthquake ruptures to the seismic hazard for Wellington for the 500 year return period is illustrated in Figure 4c, with the Wellington fault (Hutt valley segment) (M7.53), Wairarapa fault (M8.17), and Hikurangi interface sources $(M 8.2+)$ contributing $72 \%$ of the total hazard. The same trend of NZTA-BM effective magnitudes being well below the site-specific mean magnitudes is true for Whanganui, Palmerston North, Nelson, Napier, Gisborne, and Blenheim.

As previously stated, the absence of specific documentation for the methodology by which the NZTA-BM effective magnitudes have been calculated precludes further understanding of the reasons why these effective magnitudes are so low; however, the implications for magnitude-weighted PGA values for assessment and design are significant, as discussed in Cubrinovski et al. [8].

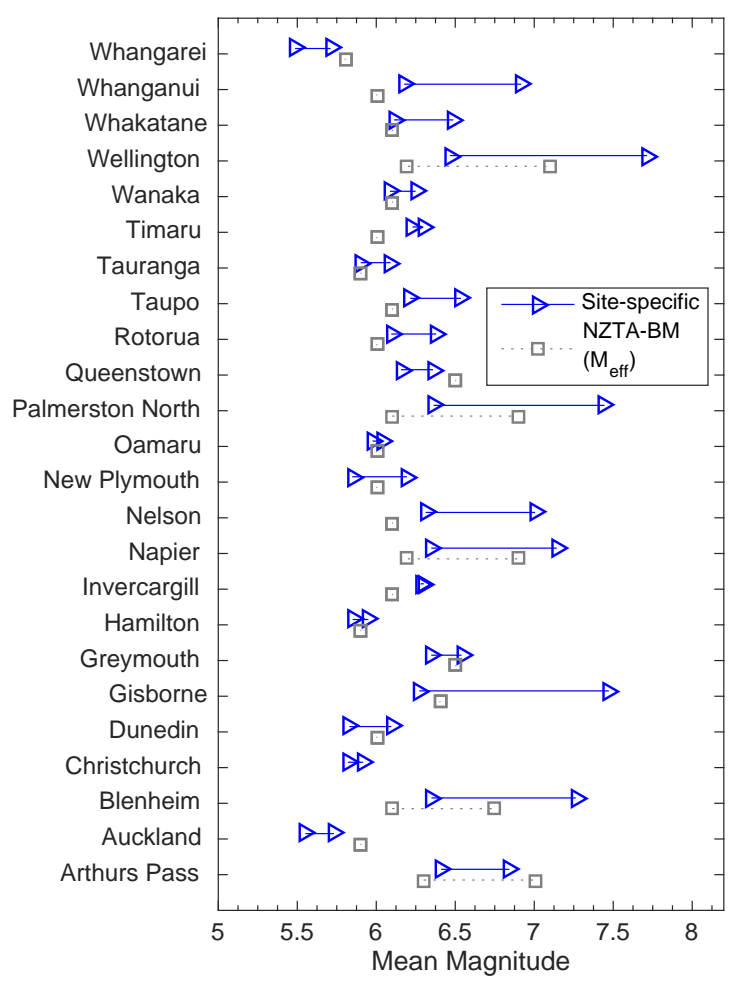

Figure 8: Site-specific disaggregation mean magnitude values for the 25 and 500 year return periods at 24 sites compared with the NZTA-BM effective magnitudes.

\section{Shape of the Seismic Hazard Curve}

Documents such as NZS1170.5 use a Return Period Factor, $R$, to describe the variation in seismic hazard with RP (or, equivalently, its recriprocal - exceedance rate). $R$ is a constant value for all geographic locations, for a given RP. The site-specific PSHA results in this study provide a means to examine the appropriateness of this approximation [4].

Figure 9 illustrates the PGA hazard for the 24 sites normalised by the 500 -year RP value, $P G A_{500}$, as compared with the 
NZS1170.5 R Factor. In essence, the figure provides a comparison of the shape of the normalized hazard curve. For all exceedance rates, the NZS1170.5 R factor is similar to the median $\left(50^{\text {th }}\right.$ percentile) of the 24 sites, indicating its accuracy in an average sense. However, there is a significant variation in the normalized PGA values across the 24 sites for any given exceedance probability. For $\lambda=0.04$ ( 25 year RP), the normalized PGA values range from less than 0.1 to approximately 0.3 ; compared with the NZS1170.5 R factor of 0.25. Similarly, for $\lambda=4 \times 10^{-4}$ (2500 year RP), the normalised PGA values range from approximately 1.5 to 2.9 , as compared to $R=1.8$ in NZS1170.5.

This site-specific variation in the 'shape' of the seismic hazard curve is well-recognised [29], however, given the factors of 23 difference in the normalised PGA values across the 24 sites for the 25 and 2500 year RPs, the potential errors in using the simple R-factor on a site-by-site basis are substantial.

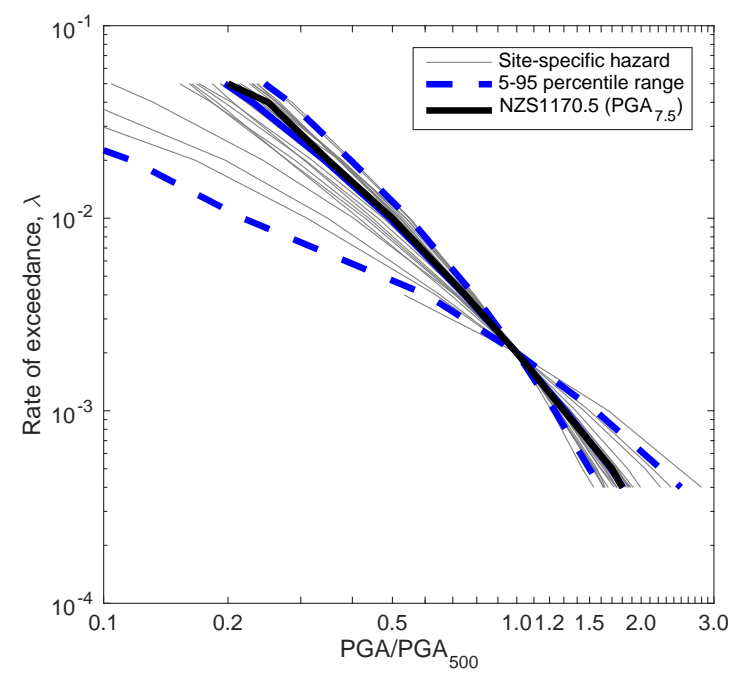

Figure 9: Site-specific PGA seismic hazard curves from 24 sites normalized by their $R P=500$ year PGA value, and compared with the NZS1170.5 Return Period Factor. The solid and dashed blue lines indicate the 5, 50, and $95^{\text {th }}$ percentiles of the 24 site-specific results.

\section{Sensitivity of PGA Hazard to Simplifying Assumptions}

The previous sections have alluded to some important limitations of simplifying assumptions that are often made in prescriptive guidance documents stipulating seismic hazard values. Figure 10 provides an illustration of the potential for error in the specified PGA hazard (expressed as a multiplicative factor) as a result of three different attributes as described below.

The first factor is associated with the difference in the seismic hazard for the two $V_{S 30}$ site conditions of $V_{S 30}=200$ and 300 $\mathrm{m} / \mathrm{s}$. Figure 5 illustrated the effect of $V_{S 30}$, and Figure 10 illustrates that an approximate 20\% error (based on the ratio of the hazard for these two site conditions across the 24 sites for the 500 year return period) can be introduced by not discriminating between these two conditions. As noted in Cubrinovski et al. [8], this error can be significantly reduced through the use of a site amplification that is a function of the ground-motion intensity.

The second factor is associated with uncertainty due to groundmotion modelling. Figure 2-Figure 4 illustrated the uncertainty in the PGA hazard (for a given exceedance rate or return period) can vary by approximately $30 \%$ as a result of the different
GMMs that comprise the consideration of GMM epistemic uncertainty. This is reflected in Figure 10 for the specific case of the Wellington PGA hazard for the 500 year return period.

The third factor is associated with the assumed 'shape' of the hazard curve. Figure 10 illustrates the range of error in the PGA hazard, using a single R-factor for the shape of the hazard curve, based on the values in Figure 9 for the 2500 year return period.

It is acknowledged that the results in Figure 10 do not represent a rigorous sensitivity analysis, and the relative sizes of the three variables are not directly compatible. That is, the site amplification range is based on 24 sites for $R P=500 \mathrm{yr}$, the GMM uncertainty range is for one site (Wellington) for $R P=500 \mathrm{yr}$, and the $\mathrm{R}$ factor range is for 24 sites for $R P=2500 \mathrm{yr}$ (since the $\mathrm{R}$ factor is normalized about $R P=500 \mathrm{yr}$ ). Nonetheless, Figure 10 provides important context for the consideration of simplifying assumptions when PSHA results are used to subsequently derive parametric expressions for using seismic hazard values in seismic assessment and design prescriptions.

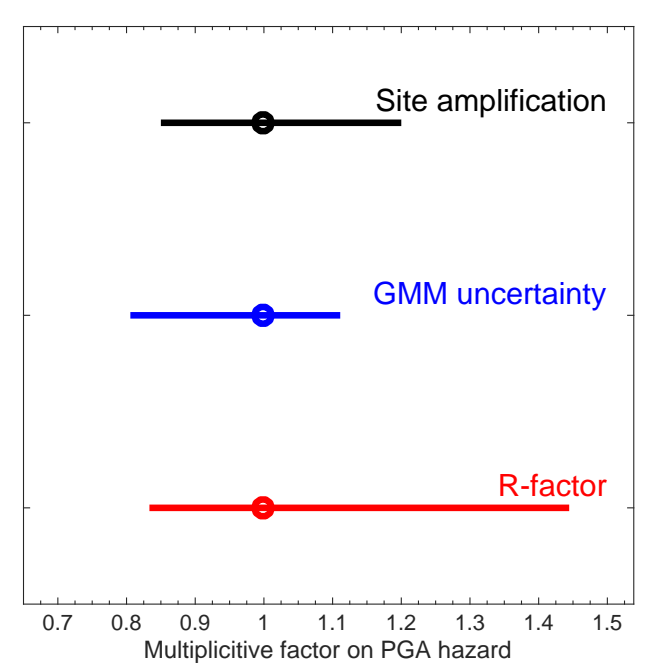
Figure 10: PGA hazard variation as a function of various simplifying factors associated with a constant site amplification, considering the mean hazard without explicitly considering GMM epistemic uncertainty, and using a constant $R$-factor instead of the site-specific shape of the hazard curve.

\section{DISCUSSION AND CONCLUSIONS}

This study has undertaken site-specific probabilistic seismic hazard analysis (PSHA) for two generic soft soil conditions and 24 locations across NZ to determine PGAs for use in geotechnical earthquake engineering applications, such as simplified liquefaction triggering assessments, slope stability analyses and retaining wall design. The adopted seismic source and groundmotion models reflect a notable advance in scientific understanding compared with those that underpin the existing standards and guidelines that are used in present practice in NZ (i.e., NZS1170.5 and NZTA-BM). The site-specific PGA values were compared against these guideline-based values for different locations, and trends identified with return period and level of seismicity.

In general, it can be concluded that the existing guidelines under-represent the true seismic hazard at locations in $\mathrm{NZ}$ with high seismicity, and also under-estimate the mean magnitude of the causative earthquake ruptures for the 500 year return period. Consequently, the design ground-motion loading for geotech- 
nical applications is appreciably under-estimated at these locations. The results presented in this study provide a scientific basis that could guide revisions to these guidance documents to more accurately reflect the accepted scientific understanding in NZ's highest seismicity regions.

The results in this study for 24 locations (sites) considered generic soil conditions, and ground-motion and seismic source models that were not tailored for the calculation of the seismic hazard at any one specific site. As such, while the results are site-specific in the sense that they are literally at a specific (set of) site(s), the rigour in geotechnical site characterisation, ground-motion and seismic source modelling are at one end of a continuum, and generally not at the same level as would be anticipated for PSHA results that are used to provide alternative solutions to the use of prescriptive guidance documents.

\section{ACKNOWLEDGMENTS}

This research was supported by the NZ Earthquake Commission, Engineering NZ, and the NZ Transport Agency. Feedback received from other members of the NZGS guidelines committee (Mike Stannard, John Scott, Nick Traylen, Kevin McManus), high-level review from Matt Gerstenberger and Elizabeth Abbot, and journal peer review from Trevor Allen are also acknowledged. Claudio Schill, Jason Motha, and Viktor Polak are acknowledged for assistance with analyses and figures.

\section{REFERENCES}

1 Standards New Zealand (2004). "NZS 1170.5:2004 Structural Design Actions, Part 5: Earthquake Actions - New Zealand": Wellington, New Zealand, 82pp.

2 NZ Transport Agency (2018). "Bridge Manual: SP//M/022. Ch6: Site-stability, Foundations, Earthworks, and Retaining Walls": Wellington, New Zealand, 52pp.

3 McGuire R (2008). "Probabilistic seismic hazard analysis: Early history". Earthquake Engineering and Structural Dynamics, 37: 329-338.

4 McVerry G (2003). "From hazard maps to code spectra for New Zealand". 2003 Pacific Conference on Earthquake Engineering: 13-15 February, Christchurch, New Zealand, 9 pp.

5 Idriss I and Boulanger R (2008). Soil Liquefaction During Earthquakes. MNO-12, Earthquake Engineering Research Institute, Oakland, CA, $261 \mathrm{pp}$.

6 Bradley BA (2015). "Benefits of site-specific hazard analyses for seismic design in New Zealand". Bulletin of the New Zealand Society for Earthquake Engineering, 48(2): 92-99. https://doi.org/10.5459/bnzsee.48.2.92-99

7 NZ Geotechnical Society (2016). "Earthquake Geotechnical Engineering Module 1 - Overview of the Guidelines": Wellington, New Zealand, 36pp.

8 Cubrinovski M, Bradley BA, Wentz F and Balachandra A (2021). "Re-evaluation of NZ seismic hazard for geotechnical assessment and design". Bulletin of New Zealand Society for Earthquake Engineering, 55(4): 1-14. https://doi. org/10.5459/bnzsee.55.1.1-14

9 Kramer S (1996). Geotechnical Earthquake Engineering. Prentice-Hall, Upper Saddle River, NJ., 653 pp.

10 Baker JW, Bradley BA and Stafford PJ (2021). Seismic Hazard and Risk Analysis. Cambridge University Press, Cambridge, UK, ISBN 978-1-108-42505-6, 594 pp.

11 Stirling M, McVerry G, Gerstenberger M, Litchfield N, Van Dissen R, Berryman K, Barnes P, Wallace L, Villamor P, Langridge R, Lamarche G, Nodder S, Reyners M, Bradley
B, Rhoades D, Smith W, Nicol A, Pettinga J, Clark K and Jacobs K (2012). "National seismic hazard model for New Zealand: 2010 update". Bulletin of the Seismological Society of America, 102(4): 1514-1542. https://doi.org/10.1785/ 0120110170

12 Bradley BA (2014). "Seismic Hazard Analysis for Urban Christchurch Accounting for the 2010-2011 Canterbury Earthquake Sequence". Tech. Rep. prepared for the New Zealand Earthquake Commission (EQC) and Tonkin \& Taylor Ltd.

13 Litchfield NJ, Van Dissen R, Sutherland R, Barnes PM, Cox SC, Norris R, Beavan RJ, Langridge R, Villamor P, Berryman K, Stirling M, Nicol A, Nodder S, Lamarche G, Barrell DJA, Pettinga JR, Little T, Pondard N, Mountjoy JJ and Clark K (2014). "A Model of active faulting in New Zealand". New Zealand Journal of Geology and Geophysics, 57(1): 32-56. https://doi.org/10.1080/00288306. 2013.854256

14 Gerstenberger M, McVerry G, Rhoades D and Stirling M (2014). "Seismic hazard modeling for the recovery of Christchurch". Earthquake Spectra, 30(1): 17-29. https: //doi.org/10.1193/021913eqs037m

15 Rhoades D, Schorlemmer D, Gerstenberger M, Christophersen A, Zechar J and Imoto M (2011). "Efficient testing of earthquake forecasting models". Acta Geophysica, 59: 728-747. https://doi.org/10.2478/s11600-011-0013-5

16 Bradley BA (2013). "A New Zealand-specific pseudospectral acceleration ground-motion prediction equation for active shallow crustal earthquakes based on foreign models". Bulletin of the Seismological Society of America, 103(3): 1801-1822. https://doi.org/10.1785/0120120021

17 Abrahamson NA, Silva WJ and Kamai R (2014). "Summary of the ASK14 ground motion relation for active crustal regions". Earthquake Spectra, 30(3): 1025-1055. https://doi. org/10.1193/070913EQS198M

18 Campbell KW and Bozorgnia Y (2014). "NGA-West2 ground motion model for the average horizontal components of PGA, PGV, and 5\% damped linear acceleration response spectra". Earthquake Spectra, 30(3): 1087-1115. https://doi.org/10.1193/062913EQS175M

19 Boore DM, Stewart JP, Seyhan E and Atkinson GM (2014). "NGA-West2 equations for predicting PGA, PGV, and 5\% damped PSA for shallow crustal earthquakes". Earthquake Spectra, 30(3): 1057-1085. https://doi.org/10.1193/ 070113EQS184M

20 Zhao J, Zhang J, Asano A, Ohno Y, Oouchi T, Takahashi T, Ogawa H, Irikura K, Thio H, Somerville P, Fukushima Y and Y F (2006). "Attenuation relations of strong ground motion in Japan using site classification based on predominant period". Bulletin of the Seismological Society of America, 96(3): 898-913. https://doi.org/10.1785/0120050122

21 Abrahamson N, Gregor N and Addo K (2016). "BC Hydro ground motion prediction equations for subduction earthquakes". Earthquake Spectra, 32(1): 23-44. https://doi.org/ 10.1193/051712EQS188MR

22 Bradley BA (2010). "NZ-specific pseudo-spectral acceleration ground motion prediction equations based on foreign models". Tech. Rep. No. 2010-03, Department of Civil and Natural Resources Engineering, University of Canterbury, Christchurch, New Zealand, 324pp.

23 Van Houtte C (2017). "Performance of response spectral models against New Zealand data". Bulletin of the New Zealand Society for Earthquake Engineering, 50(1): 21-38. https://doi.org/10.5459/bnzsee.50.1.21-38 
24 Bradley BA and Baker JW (2015). "Ground motion directionality in the 2010-2011 Canterbury earthquakes". Earthquake Engineering \& Structural Dynamics, 44(3): 371-384. https://doi.org/10.1002/eqe.2474

25 Boulanger R and Idriss I (2014). "CPT and SPT-based Liquefaction Triggering Procedures". Tech. Rep. UCD/CGM14/01, Department of Civil and Environmental Engineering, University of California, 138pp.

26 McVerry G, Zhao J, Abrahamson N and Somerville P (2006). "New Zealand acceleration response spectrum attenuation relations for crustal and subduction zone earthquakes". Bulletin of the New Zealand Society for Earthquake Engineering, 39(1): 1-58.

27 Foster KM, Bradley BA, McGann CR and Wotherspoon LM (2019). "A Vs30 map for New Zealand based on geologic and terrain proxy variables and field measurements". Earthquake Spectra, 35(4): 1865-1897. https://doi.org/10.1193/ 121118EQS281M

28 Stirling M, McVerry G and Berryman K (2002). "A new seismic hazard model for New Zealand". Bulletin of the Seismological Society of America, 92(5): 1878-1903. https: //doi.org/10.1785/0120010156

29 Standards New Zealand (2004). "NZS1170.5:2004 Structural Design Actions, Part 5: Earthquake Actions - New Zealand - Commentary": Wellington, New Zealand, 86pp.

30 Ang A and Tang W (2007). Probability Concepts in Engineering: Emphasis on Applications in Civil and Environmental Engineering. John Wiley \& Sons, ISBN 978-0-47172064-5, $432 \mathrm{pp}$.

\section{APPENDIX: MAGNITUDE FOR GEOTECHNICAL APPLICATION}

In liquefaction triggered, as well as other potential geotechnical applications, magnitude is used in combination with $P G A$ to characterise the seismic loading. Specifically, in the liquefaction triggering calculation, a single metric is the magnitudeweighted PGA value $-P G A_{7.5}=P G A \times M S F$. When multiple seismic sources contribute to the hazard (as is generally the case), the $P G A_{7.5}$ hazard should be mathematically computed as:

$$
P G A_{7.5}=\sum_{i=1}^{N_{R u p}} P G A_{i} \times M S F\left(M_{i}\right) \times w_{i}
$$

where $P G A_{i}$ is the PGA due to rupture $i, M_{i}$ and $M S F$ is the (moment) magnitude and corresponding Magnitude-Scaling Factor of that rupture, and $w_{i}$ is the probability contribution (weight) of that source to the hazard. For a specific hazard level (i.e., corresponding to a specific return period), the value of $P G A_{i}$ is constant for all $i$; and $w_{i}$ are the disaggregation probabilities $\left(P_{i}\right)$. Hence, this equation can be equally expressed as:

$$
P G A_{7.5}=P G A \sum_{i=1}^{N_{R u p}} M S F\left(M_{i}\right) \times P_{i}
$$

While $P G A_{7.5}$ is rigorously obtained in this manner, the conventional situation is that the seismic hazard for $P G A$ (unweighted) is obtained, and the magnitude weighting is subsequently applied in geotechnical design and assessment on a site-specific basis. This approach is also a necessity in the context that $M S F$ is typically a function of geotechnical characteristics (e.g., see Figure 2 of Cubrinovski et al. [8]). Furthermore, it is not common for the entire disaggregation distribution to be available in prescriptive guidelines, and instead summary statistics such as the mean, median, or modal magnitude values from the distribution are provided. The question then becomes - which single value should be utilised?

From a first-order Taylor Series expansion [30], the First-order Second Moment approach provides an approximation for the mean value of a function. That is, if:

$$
Z=\sum Y(X) P_{X}
$$

Then:

$$
\bar{Z} \approx Y(\bar{X})
$$

where the overline indicates the mean of the variable of interest. Applying this approximation to Equation 4 gives:

$$
\overline{P G A}_{7.5} \approx P G A \times \operatorname{MSF}(\bar{M})
$$

where $\bar{M}$ is the mean magnitude.

Equation 7 states that the best-estimate of $P G A_{7.5}$, is obtained using the mean magnitude, $\bar{M}$, in the absence of direct evaluation by summing over all contributing ruptures (i.e., Equation 4). 